\title{
High School Physical Education and its Effect on Fitness Facility Participation After Graduation: A Case Study 中學畢業後對使用健身設施的影響 : 案例研究
}

\author{
David BARNEY Nathan KAHAIALII \\ Brigham Young University, U.S.A.
}

\begin{abstract}
迎
Abstract

For those that send off their child into the world, it is hoped they will recall what was taught to them. This applies to high school (HS) physical education (PE) teachers and their students that graduate from HS. The purpose of this case study was to assess current HS PE effect in fitness facility participation by interviewing HS PE teachers, fitness facility personnel, current fitness facility participants and current HS students. Participants from these four groups were interviewed to help better understand the preparation of graduated HS students participating in a fitness facility. From this case study three of the four groups felt they had and were being prepared to be successful in health clubs and those activities that are found in health clubs. This study sheds light on the fact that HS PE is the last opportunity of a student to be involved in an organized class that has real world application.
\end{abstract}

\section{Introduction}

For many parent's it is hoped that they have taught their children the proper skills that will help them be successful adults when they leave their homes to go out into the world. To a certain degree high school (HS) physical education (PE) teachers feel the same about their students when they graduate and go out into the world. PE teachers hope they have taught their students the appropriate and necessary skills to be successful adults when it involves being physically active throughout their whole life. The National Association for Sport and Physical Education (NASPE, 2004) document regarding Appropriate Practices in High School Physical Education states "the primary purpose of physical education is to help adolescents gain skills and knowledge to be physically active for a lifetime" (p.5). Also, along this line The Centers for Disease Control and Prevention (2001, p.7) has described the purpose of HS PE as "increasing student participation in moderate to vigorous physical activity and to help high school students gain the knowledge, attitudes, and skills they need to engage in lifelong physical activity." These statements emphasize the impact HS PE can have on a student throughout their life.
Because of the impact HS PE can have on students, the Society of Health and Physical Educators (SHAPE America) has established national standards for K-12 grade levels (SHAPE America-Society of Health and Physical Educators, 2014). The purpose of national standards are to assist physical educators with what a student should know and be able to do (NASPE, 2004). Thus, these national standards guide physical educators in what and how they teach in their lessons and activities to students, so that student's will know and be able to do throughout their life. National standards give substance to PE lessons and activities. Physical educators are not merely "rolling out the ball" during PE class, but have goals and objectives for the lessons and activities. The national standards consist of five standards. For each standard, they specifically address physical education for students in grades $\mathrm{K}-5,6-8$, and 9-12. The outcomes for HS students in PE are, "The learner will be college or career ready as demonstrated by the ability to plan and implement different types of personal fitness programs...model responsible behaviors while engaged in physical activity." Standard three states, "Demonstrate the knowledge and skills to achieve a health-enhancing level of physical activity and fitness." Within this standard HS physical educators are to teach HS students to implement a strength and conditioning 
program, to know how to keep their heart rate in the target zone, create methods of assessing the fitness activities and goals, and many other health related activities. One way HS PE can achieve these national standards is having student participate in activities that are commonly found in fitness facilities, during the students HS years. The model most used is called the health club model. The purpose of this model in HS $\mathrm{PE}$ is to prepare students to be successful in a fitness facility setting after they have left high school (Hastie, 2003).

The literature reveals the impact of the health club model, and the positive effects on students in their HS PE class. Prusak and colleauges (2011) have defined the health club model as:

"Offerings should include sports, dance, recreational activities, a variety of fitness activities, nutrition awareness and counseling, wellness assessments, and well skills. But, as envisioned, it would also extend its reach beyond the four walls of the gym and even the school to include entire communities. Patrons may then choose from a smorgasbord of activities and information suited to their individual needs. Those who like to specialize in one sport can do so. Those who wish for more variety are accommodated. Those who want a health/fitness/wellness assessment and prescription find what they need. Those who wish to participate before or after regular school hours may do so. Those who like a little of everything can have it!"

Timken, McNamee and Coste (2017) studied adolescent girls' perceptions of their health club experience in their PE class. For this study 17 female students participated in this study. For the lesson structure, $40 \%$ of the lesson was spent in cardiovascular activities, $40 \%$ in resistance training and $20 \%$ flexibility. Such activities students participated in during the lesson were Pilates, yoga, physioball, Tae Bo, and aerobic dance to name a few. The results from the student's health club experience in their HS PE class was feelings of autonomy and relatedness. The researchers suggested that PE teachers should offer both variety and choice in PE classes to facilitate a students' sense of autonomy and relatedness. Another study dealing with female HS student's studied perceptions of selected fitness activities (Wilkinson \& Bretzing, 2011). More specifically, female students preferred the fitness units. Also, the reasons for the female preference to the fitness units, were there applicability to fitness clubs. For this study tenth grade female students participated in fitness concepts for twoweeks. Students participated in aerobics, step aerobics, kickboxing, Pilates, core training (using mats, balls, bands and dumbbells) and fitness games. After the two-week units, students could then sign up for longer units (running the whole semester) to participate in. Prior to this tenth grade course, students participated in team and individual sport activity courses, during the $7^{\text {th }}$ through $9^{\text {th }}$ grades. Shortly after the longer fitness units, the students completed a questionnaire. Results from this study found that fitness activities were preferred for many reasons. Students voiced that fitness activities created a better environment for health benefits, were fun, the variety of the activities were good, and the fitness activities consisted of easier skills than sports. The researchers also stated that the students made connections that these fitness activities could be done throughout their lives.

Barney, Pleban, Wilkinson, and Prusak (2015) studied college students' HS PE experience on their physical activity after HS. For this study, over one thousand students were surveyed. College students that were surveyed, tended to want skills in HS PE that they could use throughout their lives, such as golf, tennis, outdoor activities and weight training. A large majority of the college students in this study were not exposed to lifetime activities. An interesting point from this study was that when these college students were in HS PE, many enjoyed and excelled in team sports activities (basketball, volleyball, softball, etc.), which many of their PE teachers instituted in their HS PE courses. Yet, in hindsight, these college students indicated a desire of having been taught and exposed to activities that would have been beneficial to them later in life. Another point from this study was that the college students felt that they were not given the knowledge and skills to be successful being physically active throughout their lives. With these kinds of results HS PE teachers are in a position of exposing HS students to activities in which they can have success throughout their lives.

When conducting research, it is to the researchers' benefit to have a theoretical or conceptual framework to establish their study (Ennis, 1999). Yet, for this study, a case study methodology was used. When researching an educational context Shulman (1992) has stated that it (case study methodology) can be complex, demanding and 
nuances that requires judgements to bring elements to light. Along these same lines, Stenhouse (1980) stated regarding judgements made in a case study:

"To make refined judgements about what educational action to take in particular cases lodged in particular context, we need much more information than can at present be reduced to indices and we need to present our conclusions in a way that educates them rather than brief them" (pg. 3).

With these results from the literature and the research methodology used, the purpose of this case study was to assess HS PE effect on fitness facility participation by interviewing HS PE teachers, fitness facility personnel, current fitness facility participants and current HS students.

\section{Methods}

For this case study, the fitness facility is a facility where someone can go and participate in a number of activities from lifting weights, to swimming, participating in Zumba and yoga to playing basketball. Also, the fitness facility can be categorized as a private company (Vasa fitness, Gold's gym, \& Planet fitness) or a community recreation center. Both types of facilities, for the purpose for someone to go and workout.

\section{Participants}

The participants for this case study were a sample of convenience. Five current female HS PE teachers with 1 to 25 years of teaching experience, four fitness facility personnel (1 male and 3 females) and four (2 males and 2 females) adults that workout at the local fitness facilities, and three high school students (1 male and 2 females (See Figure 1).

\section{Procedures}

For this case study, the participants were interviewed relating to their connection to the case being investigated. The interviews were semi-structured and were audio-recorded. The interviews were designed to get the participants perspective relating to $\mathrm{HS} \mathrm{PE}$ and their activity in their local fitness facility and eventually participation at a fitness facility. Interviews were generally 20 minutes in length and was transcribed and analyzed. For the analysis of the interviews, participant responses were correlated and reviewed to generate preliminary coding categories, with framework analysis methodology for participant responses, as outlined by Check and Schutt (2011). Framework analysis incorporated the stages of 1) familiarization, 2) thematic, 3) identification, and 4) charting and interpretation (Rabiee, 2004). Additionally, investigators secured university institutional review board (IRB) approval to conduct the study.

\section{Results}

Themes emerged from the interview data, which is presented in this section from the transcribed interviews. The following themes from the data came from the four groups of participants: 1) fitness center personnel, 2) HS PE teachers, 3) Participants of the fitness center, and 4) current HS students that were enrolled in a PE class.

\section{Fitness Facility Personal}

The fitness facility personnel was of the opinion that participants that recently graduated from HS weren't as knowledgeable when they first come to the fitness center. Bob a manager of one of the fitness center stated:

"From my observations, people that have recently graduated from HS come to the fitness center with a look of uncertainty. When this happens, we give them a personal trainer to help them get started and to become confident in their surroundings. I feel if the trainer helps with what they want there is a higher likelihood that this person will keep coming back to the fitness center to work out. This is good business for the company."

Another theme that came up from the fitness center personal was that the fitness center focuses on functional fitness. Ann, one of the HS PE teachers that participated in this study described functional fitness as "those things that use multiple systems of the body simultaneously just as we would use them in our ever day lives." Josh, one of the fitness center personal stated:

"Here at our fitness center we emphasize functional fitness. We have elliptical machines, weight machines, yoga and Zumba that are offered. Right now, functional fitness is a popular workout term 
in the fitness industry. The going thing. So this is what we present to our clients. The graduated HS student that comes to our center say they have heard of functional fitness, but didn't do it as much in HS PE. We are more than happy to introduce them to the concepts and exercises dealing with functional fitness."

\section{High School PE Teachers}

The HS PE teachers strongly felt they were preparing their students to be successful at the local fitness centers. The HS PE teachers were asked if their students were to walk into the local fitness center would they know what to do and have a successful workout. Ann stated:

"We expose our students to the things they will find at a fitness center. They learned how to use the cardio machines effectively, they learned how to use machines and free weights correctly. Our teachers were licensed in various fitness exercises (i.e. crossfit, Zumba, kickboxing, etc.). So, if students were to go to a gym they would find people with the exact same skills and expertise as their HS PE teachers. And they would not be intimidated by the weight slamming, the number of people in a class, or any of the equipment. They know how to use it and us it well! The other thing our students know is the lingo and the literacy used in a fitness facility."

Another theme that came from the HS PE teachers was that their students will be informed consumers when it comes to using a fitness center. Ann's statement above touches upon her students being informed consumers. Rebecca also feels her students will be informed consumers when she stated:

"Every activity we teach at Rocky Mountain High School (pseudonym name for the school) is geared towards graduating educated consumers who feel confident in participating in many group fitness activities and individualized training programs. Our $P E$ activities are all taught in local gyms and recreation centers so that after graduation, students can participate in a variety of activities to maintain personal fitness."

\section{Participants at the Fitness Center}

A theme that came from those that currently use their local fitness center was the emphasis of weight training throughout their life. Jon stated:

"When I was in HS, my PE teacher had us work on upper body one day, the next day work on lower body. As a class, we would rotate our lifts. This has stuck with me to this day. When I was in HS I thought you lifted as much as you could and often. My HS PE teacher taught that your body needs a day off. I still use this principle in my work outs."

Another perspective dealing with this theme came from Stan when he stated:

"It was impressed upon me the importance of physical activity and all the ways to be physically active. Yet, I felt I wasn't taught the lifts that would help me maintain my muscle and strength through lifting weights. When I went to the gym I observed other lifting and saw how they were doing them. I would also look on online at certain lifts and how to execute the lift correctly."

\section{Current High School Students}

One of the themes that current HS students discussed regarding their experience in their PE class dealt with feeling confident and comfortable when they would use the local fitness center. Clark stated:

"In HS we used free weights. I was taught a variety of lifts that were helpful for me. I also have a knowledge of the safety of lifting. One other thing we were taught was the proper mechanics of lifting so that we wouldn't hurt ourselves when we lifted." Another theme discussed was when they work out at the local fitness center, they would like and appreciate working out with a friend. Amy stated, "I plan on working out at the fitness center after I graduate from HS. But, I will do it with a friend. I don't think it would be as overwhelming." Susan stated, "working out doesn't bother me. I would just like to do it with a friend." 


\section{Discussion}

The purpose of this case study was to assess HS PE effect on fitness facility participation by interviewing HS PE teachers, fitness facility personnel, current fitness facility participants and current HS students. From this case study, HS PE is teaching and exposing HS students to lifetime activities to promote their health and personal wellness (Pangrazi, 2003). From the HS PE teacher perspective, they feel they are putting their students in a position to know how to be physically active in a fitness center or in other contexts. One of the HS PE teachers stated that the activities the students are exposed to, make it possible for them to not be intimidated when they walk into a fitness center or other activity settings. Gentry and Escalante (2018) suggested that HS PE teachers need to expose HS students to lifetime activities to better prepare them to be physically active in their lives. The HS PE teachers in this case study feel they are achieving this in their classes. The fitness center personnel were of the opinion that not all recently graduated HS students come to their center confident and/or comfortable when they first come to the center. These findings are similar to Westcott's (1992) findings, dealing with recently graduated HS students. These fitness facility personnel feel that when they are instructed by their trainers there is a strong likelihood that these recently graduated HS students will continue to attend their facility. With this being said one of the fitness facility personnel feels this is good business for their company. This strongly implies that the fitness center personnel are interested in the financial profits that will come to the center.

The participants of the fitness facility looked upon their HS PE experience as shaping their attitudes towards being physically active. One of the participants stated that when she was in HS the PE teacher continually stressed the importance of being physically active. One of the HS PE teachers in this case study stated that she informs her students why the activities the students are participating in are important to them. She stated, "I want them to know the "why's of what they are doing in class." And finally, for the current HS students at this stage in their life feel they can have success in a fitness center after they graduate from HS. They expressed enjoying the curriculum in their classes, which gives them the confidence to continue their physical activity at a fitness center. These findings are opposite of what Rikard and Banville (2006) found with HS students. One of their findings from their research was that HS students did not like fitness activities and that other units in the curriculum were monotonous. Another opinion voiced by the current HS students was that when they graduate from HS and start to attend their local fitness facility they would feel more comfortable having a friend with them when they attend the fitness facility. This finding emphasizes the importance of the sociality in a physical activity context. Hohepa, Schofield and Kolt (2006) identified friends playing a large part in HS students continuing to be physically active. It was mentioned that friends can serve as motivation when exercising and also helping to maintain and stay with their physical activity. One last point that was made that could help HS students feel more comfortable and help encourage regular participation at a fitness facility would be to bring HS students to the fitness facility to see it firsthand. One of the fitness facility personnel stated, "From a business perspective, if the HS PE teacher could bring their students to the fitness facility they could see how the facility is set up and the general workings of the gym." This statement from the fitness facility personnel is solely focused to making money for the fitness company. Yet, taking HS students to the local fitness facility would also benefit the HS students. As stated, they could see first-hand how the facility is laid out, what activities are offered, what types of weights and weight machines they have for the clientele and also establish a level of comfort for the HS students to encourage participation at the facility. The results of this study help add to the literature that HS PE is doing its job in promoting, exposing HS students to the lifelong benefits of physical activity through participation at their local fitness facility. Locke (2006) has stated that these types of results, that are positive and positively promote the value and importance of $\mathrm{PE}$ need to be brought to the fore front of society.

This case study analyzed four groups that have or had a stake in HS PE. The four groups have shed light on the importance of HS PE preparing students to be successful in a fitness facility context after graduation. High school PE is the last opportunity for HS students to be exposed to structured lessons and activities (Barney \& McGaha, 2006 \& Smith \& Lounsberry, 2013). With this being the last opportunity for HS students, this can affect their attitudes towards being physically active throughout their life. 


\section{Conclusions}

The purpose of this case study was to HS PE effect on fitness facility participation by interviewing HS PE teachers, fitness facility personnel, current fitness facility participants and current HS students. The investigators anticipated that the four groups would shed light on their perspectives regarding HS PE and its effectiveness. From this case study, the HS PE teachers are in the best position to be a positive and lasting influence on their students. The HS PE teacher is preparing their students to be independent and smarter consumers of their fitness choices. In so doing HS PE teachers are helping their students feel confident when they participate in their local fitness facility. Also, HS PE teachers need to continue to be vigilant to produce a curriculum that will best benefit HS student's participation after graduation at their local fitness facilities. Barney et. al., (2015) stated, "High school physical educators are in a position to influence students to participate in regular and practical physical activities throughout their lives by exposing them to activities in which they can participate throughout their lives." A final conclusion is that HS PE is an important part of a students' education. It provides the HS student with the knowledge, with experiences to make applications to benefit their life through being physically active. Pangrazi (2003) stated, "A key measure of success at this level (HS PE) is whether students can interface successfully in community and sport clubs." From the four groups that participated in this case study, HS PE is that part of the students' education that can aid them throughout their lives.

\section{References}

Barney, D., \& McGaha, P. (2006). College students' perspectives and after course participation in basketball and tennis classes. Journal of International Council for Health, Physical Education, Recreation, Sport and Dance, XLII, (3), 23-26.

Barney, D., Pleban, F.T., Wilkinson, C., \& Prusak, K. (2015). Identifying high school physical education physical activity patterns after high school. The Physical Educator, 72, 278-293.

Centers for Disease Control and Prevention. (2001). Increasing physical activity: A report on recommendations of the Task Force on Community Preventive Services. MMWR. 50(No. RR-18).
Check, J., \& Schutt, R. (2011). Research methods in education. Thousand Oak, CA: Sage.

Gentry, C., \& Escalante, G. (2018). The weight room: Preparing students for physical activity beyond physical education. Journal of Physical Education, Recreation and Dance, 89, (6), 62-65.

Hastie, P. (2003). Teaching for lifetime physical activity through quality high school physical education. ( $1^{\text {st }}$ ed.). San Francisco, CA: Benjamin Cummings.

Hohepa, M., Schofield, G., \& Kolt, G. (2006). Physical activity: What do high school students think? Journal of Adolescent Health, 39,328-336.

Locke, L. (2006, October). Keynote Address. Paper presented at the PETE Conference, Long Beach, CA.

National Association for Sport and Physical Education. (2004). Appropriate practices for high school physical education. Reston, VA: Author.

Pangrazi, R.P. (2003). Physical education K-12: "All for one and one for all." Quest, 55, 105-117.

Prusak, K., Vincent-Graser, S., Pennington, T., Zanandrea, M., Wilkinson, C., \& Hager, R. (2011). A critical look at physical education and what must be done to address obesity issues. Journal of Physical Education, Recreation and Dance, 82, 39-46.

Rikard, G.L., \& Banville,D. (2006). High school student attitudes about physical education. Sport, Education and Society, 11(4), 385-400.

Shulman, L. (1992). Toward a pedagogy of cases. In L. Shulman (Ed.), Case methods in teacher education (pp.1-30). New York, NY: Teachers College Press.

Stenhouse, L. (1980). The study of sample and the case study of cases. British Educational Research Journal, 6 (1), 1-6.

Smith, N.J., Lounsberry, M., \& McKenzie, T. (2013). Physical activity in high school physical education: Impact of lesson context and class gender composition. Journal of Physical Activity and Health, 11, 127-135. 
Society of Health and Physical Educators. (2014). National standards \& grade-level outcomes for $\mathrm{K}$ 12 physical education. Champaign, IL: Human Kinetics.

Timken, G., McNamee, J., \& Coste, S. (2017). 'It doesn't seem like pe and I love it': Adolescent girls view of a health club physical education approach. European Physical Education Review, 22, $1-16$.

Westcott, W.L. (1992). High school physical education: A fitness professional's perspective. Quest, 44. 342-351.

Wilkinson, C., \& Bretzing, R. (2011). High school girls' perceptions of selected fitness activities. The Physical Educator, 68(2), 58-65.

\section{Correspondence}

David Barney, Ed.D.

Associate Professor

Brigham Young University

249G Smith Fieldhouse

Provo, Utah 84602

(801) $422-6477$

(801) $422-0930$

Email: David_Barney@byu.edu

Figure 1. The interrelationship between HS PE teachers, fitness club personnel, fitness center participants and current HS students.

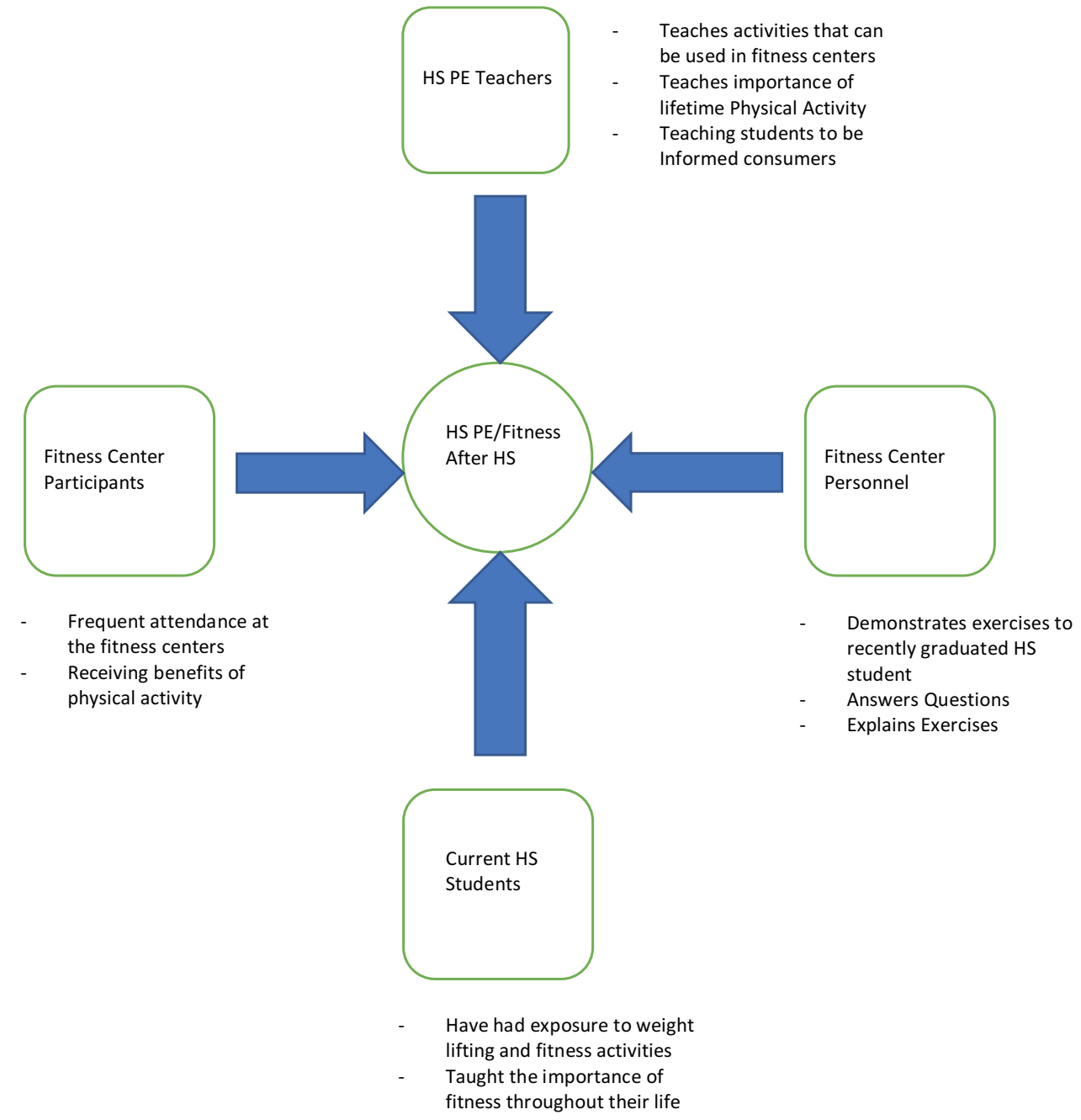

